\title{
College Adjustment in University of Michigan Students with Crohn's and Colitis
}

\author{
Jeremy Adler, MD, ${ }^{*}$ Sheela Raju, MPH, ${ }^{\#}$ Allison S. Beveridge, BS, ${ }^{\star}$ Sijian Wang, PhD, ${ }^{\natural} J i Z h u, P h D,{ }^{\S}$ and \\ Ellen M. Zimmermann, $M D^{+}$
}

\begin{abstract}
Background: Adjustment to college is critical for academic success. Poor college adjustment correlates with poor academic performance, low graduation rates, and poor success later in life. Limited data are available on the effects of inflammatory bowel disease (IBD) on college adjustment. We hypothesize that disease activity negatively impacts on QOL, and adversely affects college adjustment.
\end{abstract}

Methods: Undergraduate students (6 Crohn's disease [CD], 12 ulcerative colitis [UC], 19 healthy controls) completed a standardized college adjustment survey (SACQ) and QOL instrument (SF12). Where appropriate, disease specific activity and QOL indices were obtained (HBI, SCCAI, SIBDQ).

Results: There was an inverse correlation between disease activity and college adjustment in CD and UC $(\mathrm{R}=-0.6554, \mathrm{p}=0.0032)$. IBD students had lower physical QOL (SF-12) than controls ( $\mathrm{p}=$ 0.0009). Emotional domain of college adjustment correlated best with SIBDQ $(\mathrm{R}=0.8228, \mathrm{p}<0.0001)$, and correlated better in CD $(\mathrm{R}=0.8619)$ than UC $(\mathrm{R}=0.7946)$. Mental QOL (SF-12) was worse in $\mathrm{CD}$ than $\mathrm{UC}(\mathrm{p}=0.0211)$, but neither differed from controls $(\mathrm{p}=0.4, \mathrm{p}=0.6)$.

Conclusions: Students with active Crohn's and colitis adjust less well to college life. Physical and emotional factors likely contribute. More aggressive medical therapy and better emotional support before and during college may result in happier and healthier college students, leading to higher graduation rates and future success. Interventions resulting in better disease control

Received for publication January 8, 2008; Accepted March 17, 2008

From the *Departments of Pediatrics, Division of Gastroenterology, University of Michigan Medical School, University of Michigan, "School of Public Health, University of Michigan, Ann Arbor, Michigan, 'Department of Internal Medicine, Division of Gastroenterology, University of Michigan

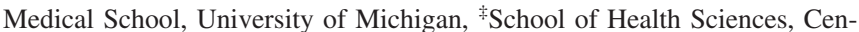
tral Michigan University, ${ }^{\S}$ Department of Statistics, University of Michigan, Ann Arbor, Michigan, "Department of Biostatistics, University of Michigan, Ann Arbor, Michigan.

Supported by Centocor and UCB Pharmaceuticals.

Reprints: Ellen Zimmermann, University of Michigan Medical School, 1500 E. Medical Center Dr., Ann Arbor, MI 48109 (e-mail: ezimmer@ umich.edu).

Copyright (C) 2008 Crohn's \& Colitis Foundation of America, Inc. DOI 10.1002/ibd.20484

Published online 29 May 2008 in Wiley InterScience (www.interscience. wiley.com). and support systems may improve college performance and provide long-term benefits to young adults with IBD.

(Inflamm Bowel Dis 2008;14:1281-1286)

Key Words: Crohn's disease, clinical areas, disease activity, adolescent medicine, college adjustment, pediatrics, psychosocial aspects of IBD, quality of life

S tudents who adjust well to college get better grades, are $\checkmark$ more likely to graduate, and are more successful later in life. ${ }^{1,2}$ Many factors influence how likely a student is to adjust well to college, including family stressors, social interactions, and physical health. Little is known about how students with chronic illnesses adapt to the challenges and demands of college life. ${ }^{3,4}$ Even less is known about how students with inflammatory bowel disease (IBD) adjust to college.

Students with chronic illnesses have a difficult time adjusting to life-changing events in general. ${ }^{5}$ Adolescents with chronic illnesses have been shown to have a greater difficulty with transition to college than their healthy peers, ${ }^{3}$ and young adults with chronic medical conditions reach significantly lower levels of educational attainment than their healthy peers. ${ }^{4}$

Students with IBD, like others with chronic illnesses, have greater perceived stress than the majority of college freshmen. ${ }^{6}$ Perceived psychological stress has an impact on any student's ability to adjust to college. ${ }^{1,7}$ In students with IBD, it is not clear how stress is related to disease activity, and it is not clear how disease activity specifically affects a student's adjustment to college. Graff et $\mathrm{al}^{8}$ demonstrated that disease activity negatively impacts both psychological functioning and disease-specific quality of life (QOL). However, stressful life events in and of themselves have been inconsistently correlated with increased disease activity in students with IBD. ${ }^{6}$

The aim of this pilot study was to compare the results of a standardized college adjustment survey in a group of students with IBD with students without IBD. Our objective was to determine to what degree disease activity impacts college adjustment. To our knowledge this is the first study assessing college adjustment in students with IBD. Information gained from a detailed study of college students should be useful to students, parents, university administration offi- 


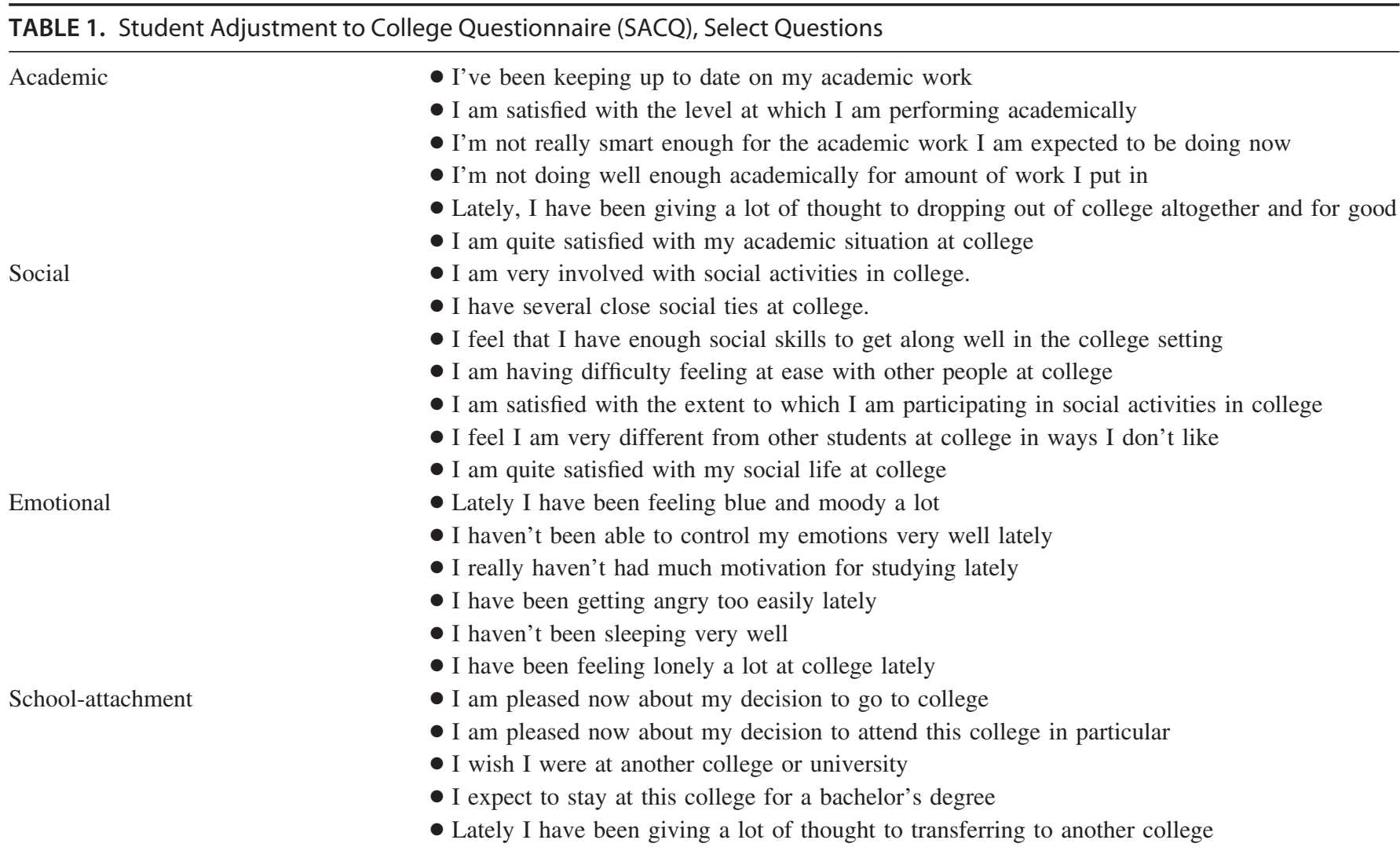

cials, and physicians. Our hope is that this pilot study will result in new interest in studying this frequently overlooked population, with the ultimate goal of designing interventions that will ease the transition to college and result in improved college performance and future success.

\section{MATERIALS AND METHODS}

This case-controlled study was conducted at the University of Michigan (UM) from September 2003 to April 2006 and was approved by the University of Michigan Institutional Review Board. To recruit case participants an email was sent out to the UM student IBD group, a support and information group on campus for UM students with Crohn's disease (CD) and ulcerative colitis (UC). Students were also referred by their physicians and advertisements were posted in the student newspaper and the University Health Services building. Twenty-eight undergraduate students with IBD were screened for comorbidities and asked standard demographic questions, consisting of age, race, and sex. Diseasespecific information was taken to establish a disease type in each case. The presence of IBD and the determination of whether the student had CD or UC was made by typical history, clinical course, diagnostic tests, and medication use. Control subjects were recruited from names provided by the case subjects of students in the same college year from their hometowns to help ensure a common socioeconomic status. The control students were screened for chronic disease. Their demographic information was recorded and matched to the IBD students for age, gender, and race.

Participants were given nominal incentives to Starbucks for completion of the surveys. Informed consent from both cases and controls was obtained and the surveys were completed in person.

\section{Survey Instruments}

Two disease-independent surveys were administered to all subjects. Student Adjustment to College Questionnaire (SACQ; Table 1) $)^{2,9}$ is an adjustment to college, self-reported survey, using 67 questions on 4 different subscales: academic, social, emotional, and school attachment. Questions focus on how well a student is adapting to the demands of college life. ${ }^{9}$ The Short Form-12 (SF-12) is a well-validated general QOL survey containing questions on physical and mental subscales. ${ }^{10}$

Several disease-specific surveys were administered to the appropriate subjects. The IBD-specific QOL questionnaire used was the Short Inflammatory Bowel Disease Questionnaire (SIBDQ). This validated questionnaire consists of 10 questions that measure the impact of IBD on social and emotional domains as well as physical symptoms. ${ }^{11,12}$ The 


\begin{tabular}{lcccr}
\hline TABLE 2. Study Demographics & & \\
\hline Characteristic & CD & UC & Control & Total \\
\hline Freshman & 1 & 2 & 2 & 5 \\
Sophomore & 0 & 1 & 2 & 3 \\
Junior & 1 & 6 & 6 & 13 \\
Senior & 4 & 3 & 9 & 16 \\
Male & 1 & $9 *$ & 7 & 17 \\
Female & 5 & 4 & 12 & 21 \\
Total number & 6 & 13 & 19 & 38 \\
\hline
\end{tabular}

*One student failed to report his year of education.

Harvey-Bradshaw Index (HBI) is a widely used, validated $\mathrm{CD}$ activity questionnaire ${ }^{13}$ consisting of symptom questions, physical examination findings, and hematocrit. Sandler et al ${ }^{14}$ developed a modified HBI questionnaire that does not include physical examination or laboratory test and was shown to correlate well with the original HBI. We used this modified HBI to assess disease activity in the students with CD. Students with UC completed the Simple Clinical Colitis Activity Index (SCCAI), a validated 16-question survey, to assess disease activity. ${ }^{15}$

\section{Statistical Analysis}

Descriptive statistics were used to evaluate demographics. Student's $t$-test was used to compare college adjustment (SACQ) and nondisease QOL (SF-12) between subjects with IBD and subjects in the control group. We also compared the disease-specific QOL (SIBDQ) and nondisease-specific QOL (SF-12) between subjects with 2 different diseases using the $t$-test. To investigate the impacts of disease activity (HBI and SCCAI) on college adjustment (SACQ) and disease-specific QOL (SIBDQ), Pearson's correlation coefficients $(R)$ were calculated from subjects with IBD. For all tests the $P$-value was 2 -sided. To assess the relationship between disease activity and scoring of individual questions we used the Cochran-Mantel-Haenszel chi-square test. Analysis was carried out using Stata for Mac v. 9.2 statistical software (College Station, TX).

\section{RESULTS}

Twenty-eight students at the UM were identified for participation in this survey. Nine students were excluded from the study due to either declining to complete (7 students) or incompletely completing the survey (2 students). Nineteen students completed the survey, 6 with CD and 13 with UC. One male student with UC failed to report his year in school but otherwise completed the entire survey. Of those students reporting year of school, $14 \%$ were freshmen, $8 \%$ were sophomores, $35 \%$ were juniors, and $43 \%$ were seniors. Study demographics are listed in Table 2.
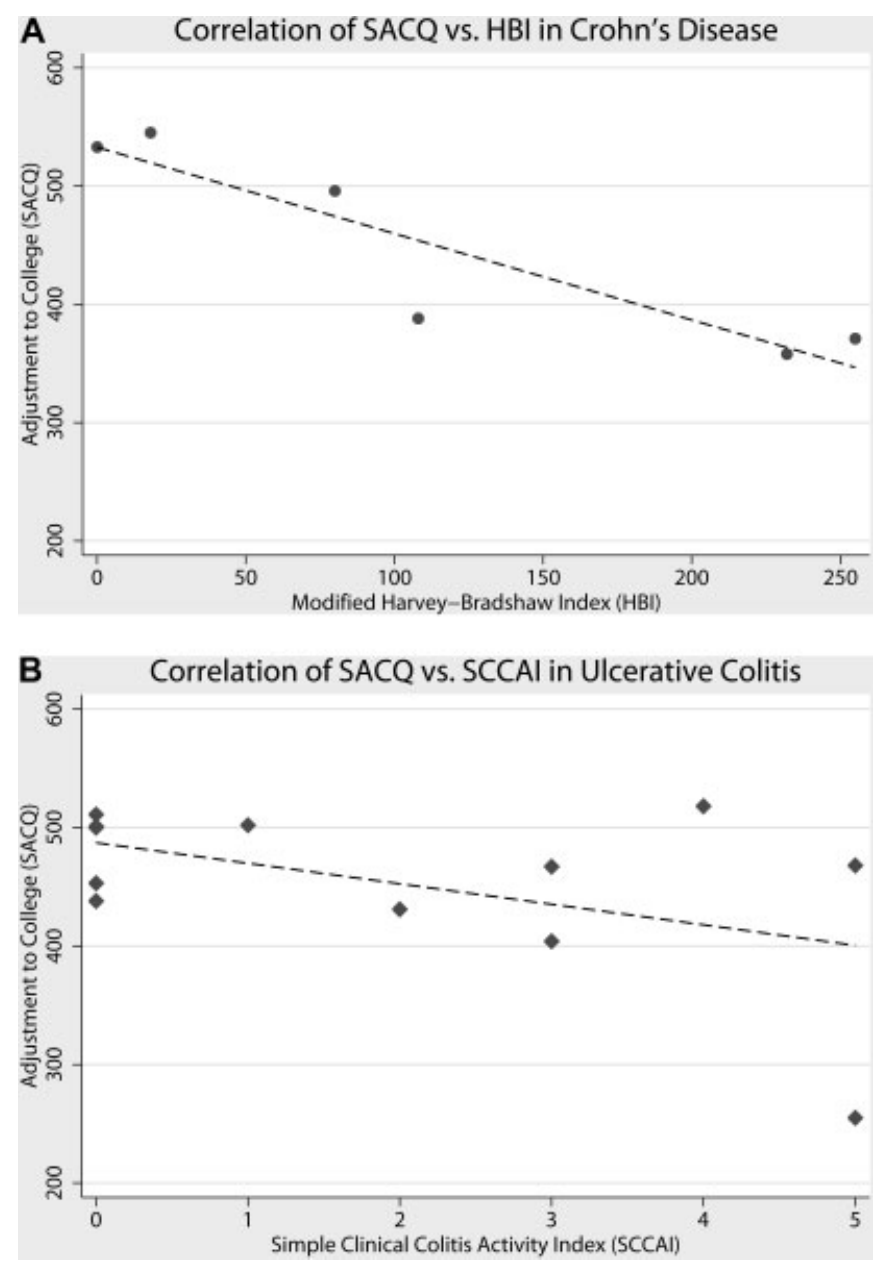

FIGURE 1. A: Inverse correlation of SACQ with $\mathrm{HBI}(R$ $=-0.9131, P=0.0110$ ) in students with CD indicating worsening disease activity is associated with poorer college adjustment. B: Inverse correlation of SACQ with SCCAI $(R=-0.4853, P$ $=0.1098$ ) in students with UC indicating worsening disease activity is associated with poorer college adjustment. Not statistically significant due to small number of students, but trend toward significance.

There was an inverse correlation between disease activity and college adjustment (SACQ) score for students with IBD. Students with CD showed a strong negative correlation between the severity of their disease as indicated by HBI compared to their SACQ score $(R=-0.9182, P=0.01$; Fig. $1 \mathrm{~A})$. There was a trend toward negative correlation between SACQ and SCCAI in students with UC but this did not reach statistical significance $(R=-0.5081, P=0.0917$; Fig. 1B). For overall assessment of IBD activity, percentiles of HBI score for CD students and SCCAI for UC students were combined. When the combined disease activity of $\mathrm{CD}$ and UC students were considered together, there was a strong negative correlation between SACQ and disease activity $(R$ $=-0.6554, P=0.0032$; Fig. 2).

The college adjustment measure SACQ correlated well 


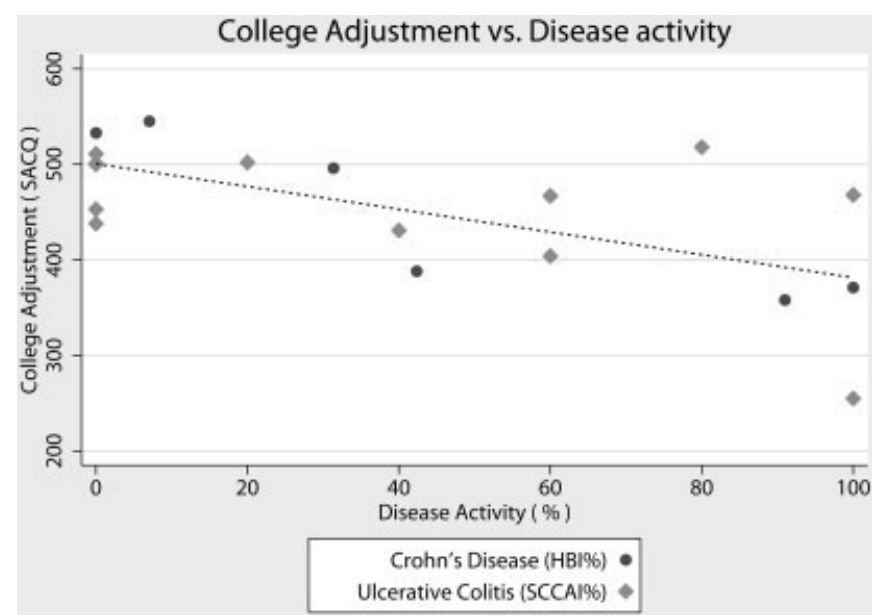

FIGURE 2. Disease activity is represented by combination of percentiles for both $\mathrm{HBI}$ and SCCAI. Note inverse association with SACQ $(R=-0.6435, P=0.004)$ indicating worse disease activity correlates with poorer college adjustment.

with the SIBDQ, a disease-specific QOL indicator $(R$ $=0.7225, P=0.0005$; Fig. 3A). The SACQ contains questions in several domains. When considered separately, the personal-emotional domain of the SACQ correlated best with the SIBDQ $(R=0.8228, P<0.0001)$, indicating more significant emotional adjustment relating to college adjustment for IBD students. SIBDQ in CD students was not different from that of UC students (49.3 versus 54.2, $P$ $=0.2553$ ); however, $\mathrm{CD}$ patients personal-emotional SACQ correlated better with SIBDQ than patients with UC $(R$ $=0.8619$ versus 0.7946 ). As expected, overall assessment of disease-specific QOL (SIBDQ) correlated with disease activity $(R=-0.6941, P=0.0014)$, indicating that disease activity negatively affects QOL (Fig. 3B).

Students with IBD overall adjusted to college as well as their healthy peers (SACQ: IBD $=444.9$; Control $=443.9$, $P=0.969)$. When individual groups of $\mathrm{CD}$ and UC students were each compared with controls they were also similarly well adjusted $(\mathrm{CD}, P=0.936$; UC, $P=0.919)$.

There were significant differences between how well women emotionally adjust to college compared to men regardless of disease status (women 83.05, men 102.22, P $=0.0122$ ). However, when gender differences were compared between IBD and controls and between CD or UC and control, no significant differences were found. There also were no differences found between female $\mathrm{CD}$ and female UC students. There was only 1 male CD students, so gender differences could not be calculated for male versus female CD.

Students with poor college adjustment (IBD and control), defined as the lowest quartile of SACQ, were more likely to report feeling unable to keep up to date with their academic work $\left(\chi^{2}=6.84, P=0.0089\right)$, reported being
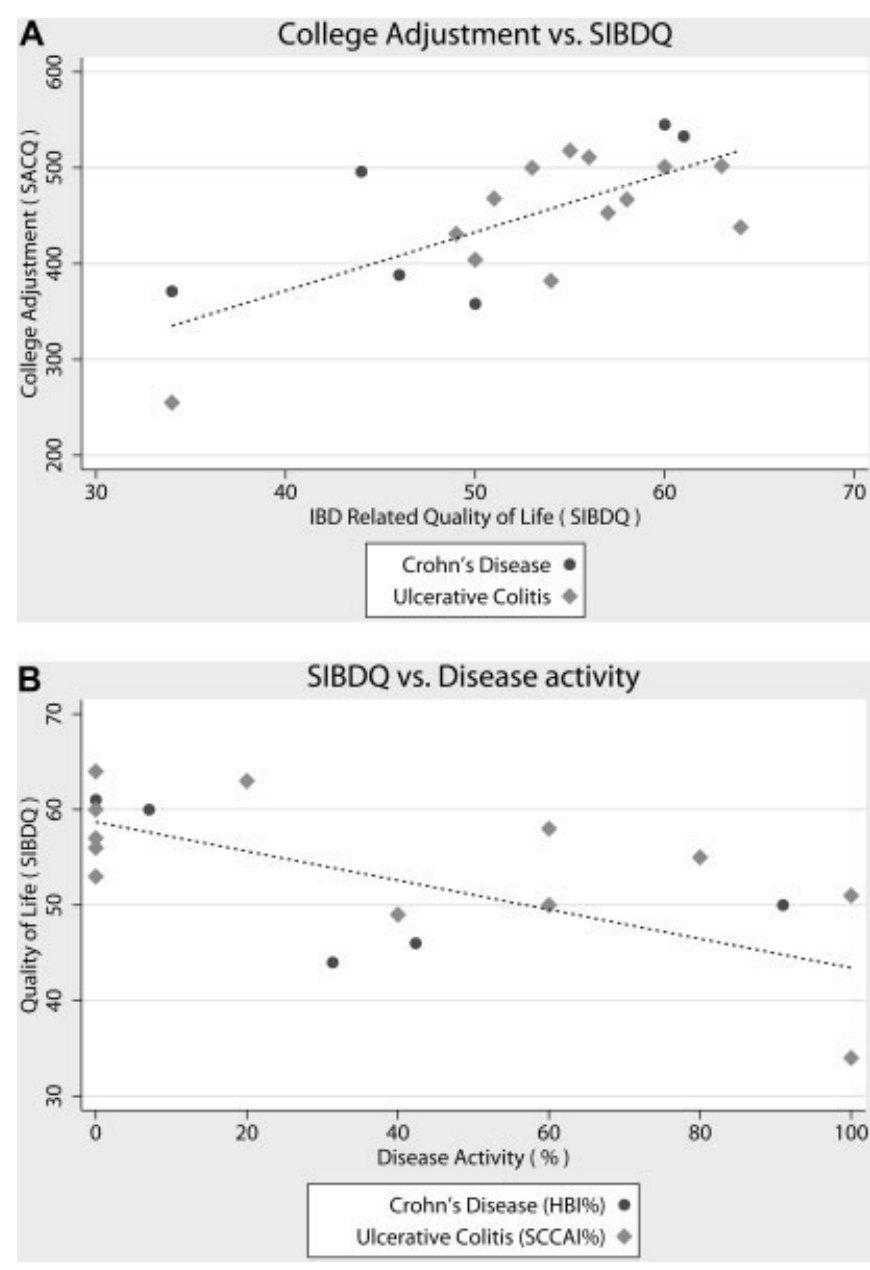

FIGURE 3. A: Disease-specific quality of life (SIBDQ) correlates well with college adjustment (SACQ; $R=0.7079, P=0.0007$ ) indicating that improved quality of life is associated with better adjustment to college. B: Disease activity is represented by combination of percentiles for both $\mathrm{HBI}$ and SCCAI. Inverse correlation with SIBDQ $(R=-0.6870, P=0.0016)$ indicates that worse disease activity is associated with poorer disease specific quality of life.

unsatisfied with their academic performance $\left(\chi^{2}=8.07, P\right.$ $=0.0045)$, had more difficulty concentrating $\left(\chi^{2}=6.0, P\right.$ $=0.0143)$, reported inefficient use of their study time $\left(\chi^{2}\right.$ $=12.55, P=0.0004)$, and not attending classes regularly $\left(\chi^{2}\right.$ $=6.84, P=0.0089)$ compared with those students who were adjusting better to college. They were also more likely to report feeling lack of confidence in being able to deal with the future challenges $\left(\chi^{2}=10.11, P=0.0015\right)$.

Students with IBD who had worse disease activity (highest quartile) were more likely to report difficulty keeping up with their academic work $\left(\chi^{2}=6.78, P=0.0092\right)$ than others with IBD. Disease activity in students with CD correlated negatively with their self-reported ability to keep up with academic work $(R=-0.886, P=0.019)$, not attending classes regularly $(R=-0.884, P=0.019)$, and 
with their reports of not feeling confident that they will be able to satisfactorily deal with future academic challenges $(R$ $=-0.8359, P=0.0382)$. Students with UC did not share these associations ( $P=0.07, P=0.9, P=0.7$, respectively).

In the physical domain of the SF-12 there was a difference between IBD students when compared to controls (48.48 versus 57.12, $P=0.0009$ ), indicating students with IBD felt more limited in their physical activity than their healthy peers. There were, however, no differences between $\mathrm{CD}$ and UC students (51.07 versus 47.29, $P=0.4192)$. In the mental domain there were substantial differences between $\mathrm{CD}$ and $\mathrm{UC}$ (39.73 versus 50.81, $P=0.0211$ ), indicating that students with $\mathrm{CD}$ felt more emotional strain than those with UC. There were no differences in the mental domain of SF-12 between either $\mathrm{CD}(P=0.4)$ or UC $(P=0.2)$ or $\operatorname{IBD}(P$ $=0.6)$ cases in general and the control students.

\section{DISCUSSION}

Successful adaptation to the social, emotional, and academic challenges of college life is essential for success in college, and for success later in life. ${ }^{1,2,4,16}$ Students' college adjustment has been shown to predict their likelihood of persisting in college to graduation; those with low adjustment scores have a higher rate of dropping out of college. Further, college graduation is an important predictor of the ability to obtain job-related health insurance. Many factors affect a student's ability to adjust to college, including independence from family, social support, self-confidence, and general level of stress. ${ }^{1,7,16}$ Little is known about the impact of chronic illness on a student's ability to adjust to college life. Our study is the first to address the role of IBD on college adjustment. We demonstrate that disease activity directly impacts the ability of students to adjust to college.

Prior studies have addressed the role of stress and chronic medical conditions on college success. Pritchard and Wilson ${ }^{16}$ demonstrated that the perceived level of stress effects a student's likelihood of success in college. In 1992, Lavigne and Faier-Routman ${ }^{5}$ performed a meta-analysis of studies demonstrating that adolescents with chronic medical conditions experienced greater difficulties with transitioning from high school to college. This was reconfirmed by Wodka and Barakat in 2007. ${ }^{3}$ Gledhill et $\mathrm{al}^{4}$ further demonstrated impaired level of educational attainment in individuals with chronic medical conditions.

The onset of IBD typically occurs in the second or third decades of life, and it is not unusual for students to be diagnosed with IBD during college. ${ }^{17-19}$ Clinical symptoms may be most severe during the first few years after diagnosis. ${ }^{20}$ The symptoms of IBD can be intrusive and disruptive of schoolwork, and can impinge on social interactions. Dealing with a chronic illness can exact an emotional toll on students who are trying to fit in with their social peer group.

We demonstrated that the ability to adjust to college correlates negatively with disease activity. The idea that if you are sick, you have trouble adjusting to college seems intuitive. However, linking disease activity with an important indicator of life outcome is new and has important implications for how students are prepared to enter college. This is a particularly difficult time because this age group often is far from home and "falls between the cracks" of pediatric and adult healthcare. A parallel can be drawn between college adjustment and pregnancy. Data on pregnancy and IBD suggest better pregnancy outcomes if students are in remission at the time of conception. Our data would support the hypothesis that the best college outcomes occur if students disease symptoms are well controlled when they enter college.

We demonstrated that IBD activity (HBI and SACCI) correlates with disease-specific QOL (SIBDQ) and with both mental and physical health-related QOL (SF-12). This confirms the findings of Pizzi et al, ${ }^{21}$ who found that IBD severity was an important predictor of QOL. We further found that SIBDQ and general state of physical health (SF-12-physical) both correlated with the student's adjustment to college as measured by SACQ.

Poor adjustment to college predicts poor academic performance and a higher likelihood of dropping out of school. ${ }^{2}$ We did not collect information on students' grades, but several questions targeted the student's own perception of their academic performance. IBD students with poor college adjustment were most likely to report feeling unable to keep up to date with academic work and being unsatisfied with their level of academic performance, and were more likely to report having difficulty concentrating while studying. Interestingly, these negative indicators correlated inversely with disease activity in students with CD. To state it in simpler terms, the sicker you are with $\mathrm{CD}$, the harder it is to concentrate and do well in college.

Our study is limited by small size and a relatively low representation in freshmen and sophomore classes. We used several recruitment methods including recruiting from the IBD student support group, from physicians, and from response to advertisements, but it is likely that our populations were slightly skewed due to selection bias. We predict that in a student population of 40,025 at UM, we would have as many as 397 students with IBD on campus. ${ }^{22}$ Our database has $\approx 150$ students identified from UM clinics, health services, Web and newspaper advertising, and posting of fliers. Yet attendance at monthly IBD support group meetings is around 20 students. This mandates that the students be identified prior to matriculating because once they enter college they are very difficult to contact and engage.

If students with more active IBD adjust more poorly to college, then they are less likely to succeed in their academic career, leading to fewer career choices, lower-paying jobs, and lower rates of health insurance. It is imperative that as clinicians we provide adolescents and young adults with the 
optimal chance of success by adequately controlling their disease. This may argue for a more aggressive "top-down" treatment approach to ensure that students are in the best possible state of health when embarking on their college education. If colleges and universities can identify students with IBD, they may be better able to ensure adequate support networks to assist in student's adjustment to college life and ensure adequate healthcare during their college years.

\section{ACKNOWLEDGMENTS}

We thank the Crohn's and Colitis Foundation for supporting 2 student fellowships (to A.B., S.E.) to study the UM IBD student group. We thank Mr. Bernard Riker, Executive Director of the Michigan Chapter of the Crohn's and Colitis Foundation, for support and direction, and Alex Aubrey, an undergraduate student at UM, who currently runs the UM Crohn's and Colitis Student Initiative (CCSI).

\section{REFERENCES}

1. Friedlander LJ, Reid GJ, Shupak N, et al. Social support, self-esteem, and stress as predictors of adjustment to university among first-year undergraduates. J Coll Student Dev. 2007;48:259-274.

2. Krotseng MV. Predicting persistence from the student adaptation to college questionnaire: early warning or siren song? Res Higher Educ. 1992;33:99-111.

3. Wodka EL, Barakat LP. An exploratory study of the relationship of family support and coping with adjustment: implications for college students with a chronic illness. J Adolesc. 2007:30:365-376.

4. Gledhill J, Rangel L, Garralda E. Surviving chronic physical illness: psychosocial outcome in adult life. Arch Dis Child. 2000;83:104-110.

5. Lavigne JV, Faier-Routman J. Psychological adjustment to pediatric physical disorders: a meta-analytic review. J Pediatr Psychol. 1992;17: 133-157.

6. Sewitch MJ, Abrahamowicz M, Bitton A, et al. Psychological distress, social support, and disease activity in patients with inflammatory bowel disease. Am J Gastroenterol. 2001;96:1470-1479.

7. Chemers MM, Hu L-T, Garcia BF. Academic self-efficacy and first year college student performance and adjustment. J Educ Psychol. 2001;93: $55-64$.
8. Graff LA, Walker JR, Lix L, et al. The relationship of inflammatory bowel disease type and activity to psychological functioning and quality of life. Clin Gastroenterol Hepatol. 2006;4:1491-1501.

9. Baker RW, Siryk B. The Student Adaptation to College Questionnaire (SACQ): Manual. Los Angeles: Western Psychological Services; 1989.

10. Gandek B, Ware JE, Aaronson NK, et al. Cross-validation of item selection and scoring for the SF-12 Health Survey in nine countries: results from the IQOLA Project. International Quality of Life Assessment. J Clin Epidemiol. 1998;51:1171-1178.

11. Jowett SL, Seal CJ, Barton JR, et al. The short inflammatory bowel disease questionnaire is reliable and responsive to clinically important change in ulcerative colitis. Am J Gastroenterol. 2001;96:2921-2928.

12. Irvine EJ, Zhou Q, Thompson AK. The Short Inflammatory Bowel Disease Questionnaire: a quality of life instrument for community physicians managing inflammatory bowel disease. CCRPT Investigators. Canadian Crohn's Relapse Prevention Trial. Am J Gastroenterol. 1996; 91:1571-1578.

13. Harvey RF, Bradshaw JM. A simple index of Crohn's-disease activity. Lancet. 1980;1:514.

14. Sandler RS, Jordan MC, Kupper LL. Development of a Crohn's index for survey research. J Clin Epidemiol. 1988;41:451-458.

15. Walmsley RS, Ayres RC, Pounder RE, et al. A simple clinical colitis activity index. Gut. 1998;43:29-32.

16. Pritchard ME, Wilson GS. Using emotional and social factors to predict student success. J Coll Student Dev. 2003;44:18-28.

17. Rogers BH, Clark LM, Kirsner JB. The epidemiologic and demographic characteristics of inflammatory bowel disease: an analysis of a computerized file of 1400 patients. J Chronic Dis. 1971;24:743-773.

18. Loftus EV Jr, Silverstein MD, Sandborn WJ, et al. Crohn's disease in Olmsted County, Minnesota, 1940-1993: incidence, prevalence, and survival. Gastroenterology. 1998;114:1161-1168.

19. Loftus EV Jr. Clinical epidemiology of inflammatory bowel disease: incidence, prevalence, and environmental influences. Gastroenterology. 2004;126:1504-1517.

20. Moum B, Ekbom A, Vatn MH, et al. Clinical course during the 1st year after diagnosis in ulcerative colitis and Crohn's disease. Results of a large, prospective population-based study in southeastern Norway, 1990-93. Scand J Gastroenterol. 1997;32:1005-1012.

21. Pizzi LT, Weston CM, Goldfarb NI, et al. Impact of chronic conditions on quality of life in patients with inflammatory bowel disease. Inflamm Bowel Dis. 2006;12:47-52.

22. Loftus CG, Loftus EV Jr, Harmsen WS, et al. Update on the incidence and prevalence of Crohn's disease and ulcerative colitis in Olmsted County, Minnesota, 1940-2000. Inflamm Bowel Dis. 2007;13:254-261. 